\title{
Simple extraction method of green crude from natural blue-green microalgae by dimethyl ether: Extraction efficiency on several species compared to the Bligh-Dyer's method
}

\author{
Hideki Kanda ${ }^{1, *}$, Peng $\mathrm{Li}^{1}$ \\ ${ }^{1}$ Energy Engineering Research Laboratory, Central Research Institute of Electric Power Industry, \\ Yokosuka, 240-0196 Japan \\ *Corresponding author. Tel: +81-46-856-2121, Fax: +81-46-856-3346, E-mail: kanda@criepi.denken.or.jp
}

\begin{abstract}
We proposed a simple, energy-efficient and environmental friendly method to extract green crude oil from microalgae by using dimethyl ether (DME). In this study, this method was tested on several species of natural blue-green microalgae. Consequently, the green crude was successfully directly extracted from highmoisture microalgae (78.2-93.4 \% water content) with an extraction rate ranging from 9.9 to $40.1 \%$ of the dry weight of the microalgae. The extraction yield of total green crude on these species by liquefied DME was compared to the widely-used Bligh-Dyer's method. The DME method almost achieved an extraction capacity approximately equivalent to the Bligh-Dyer's method. Furthermore, the dewatering properties of the proposed method on several species of wet microalgae, and the extraction efficiency were also investigated.
\end{abstract}

Keywords: Biofuel, Blue-green microalgae, Extraction, Dimethyl ether.

\section{Introduction}

Fossil fuel depletion and global warming issues have strongly motivated research on fuel production from biomass such as corps, animal fat, and micro algae [1]. Among these options, microalgae have attracted significant attention as a new generation biofuel resource [2]. Compared with terrestrial plants, microalgae have a high oil content and growth rate; mass algal cultivation can be performed on unexploited lands using systems supplied with nutrients, thus avoiding competition for limited arable lands [3].

In general, all type of microalgae biosynthesize oleic compositions. The oleic contents of many natural microalgae were approximately $20-50 \%$ of dry weight [3, 4]. The overall process related to microalgae biofuel include: species selection, microalgae cultivation, recovery of biofuel (the so-called green crude), and biofuel refining. Methods of microalgae cultivation have been widely studied [5,6]. Green crude is basically recovered from microalgae by solvent extraction.

In the conventional process, the recovery of green crude from microalgae generally requires multiple solid-liquid separation steps. These processes involve drying, cell wall disruption, and solvent extraction; on a laboratory scale [7]. The extraction of green crude is usually performed with toxic organic solvents such as hexane, chloroform, and methanol, meaning these processes are highly energy-intensive and environmentally damaging [7]. In the labscale, green crude extraction with hexane normally carried out by soxhlet at $70{ }^{\circ} \mathrm{C}$ for 18 hours [4]. This long time of extraction and heating is drawback in the hexane extraction method. The most rapid and effective conventional extraction method for green crude is the Bligh-Dyer's method [8], which uses drying, cell disruption, solvent (chloroform-methanol) extraction, and evaporation of the solvent. This method has been indispensable and standard, not only for green crude extraction from micro algae but also the quantification of the crude oil from biological materials [9-11].

In the previous study, we proposed a simpler green crude recovery method, which combined drying, cell wall disruption, solvent extraction, and solvent evaporation in a single step [12]. 
By using liquefied dimethyl ether (DME) as an extractant, green crude was extracted directly from high-moisture natural microalgae without drying and cell wall disruption. This method was conceptualized from our previously established low-energy dewatering [13-16] and deoiling method [17-19], based on the following DME characteristics, namely (i) high affinity with oil and partial miscibility in water (ii) lower boiling point and stable pressure at normal temperature (iii) harmless and naturally decomposable [20, 21].

In the conventional method, the latent heat, sensible heat of water is lost since water should be evaporated in the pretreatment. The calorific value required for heating $1 \mathrm{~g}$ of water from $20^{\circ} \mathrm{C}$ to $100^{\circ} \mathrm{C}$ and for evaporating water at $100^{\circ} \mathrm{C}$ is $2,590 \mathrm{Jg}^{-1}$. Here, the initial moisture content of the micloalgae slurry is assumed to be $90.0 \%$ [12]. Therefore, the weight of water was 9 times of the dry weight of the micloalgae. Green crude content in micloalgae is also assumed to be $20 \%$ as we will describe later. In the green crude weight basis, theoretical heat loss is 2,590 $\times 9 / 0.2=116,550 \mathrm{Jg}^{-1}$. Moreover, the calorific value required for heating $1 \mathrm{~g}$ of chloroform-methanol mixture from $20^{\circ} \mathrm{C}$ to its boiling point (approximate $63^{\circ} \mathrm{C}$ ) and for evaporating extraction solvent at $63^{\circ} \mathrm{C}$ is around $700 \mathrm{Jg}^{-1}$. This is assumed from average latent heat of chloroform $\left(247 \mathrm{Jg}^{-1}\right)$ and methanol $\left(1,155 \mathrm{Jg}^{-1}\right)$. Here, the final green crude oil concentration in the chloroform-methanol mixture is $3.3 \%$ which estimated from current study in the case of green crude content was $20 \%$. Therefore, the weight of chloroformmethanol mixture was 29.3 times of the green crude weight. Therefore, the theoretical heat loss for evaporating the chloroform-methanol mixture is $700 \times 29.3=20,510 \mathrm{Jg}^{-1}$. In addition, the energy consumed for cell disruption is unidentified and must be large. Therefore, the total required energy is roughly $137,060 \mathrm{Jg}^{-1}$ and plus the unidentified part for cell disruption.

In contrast, in the proposed method, the energy required to remove $1 \mathrm{~g}$ of water is $1,109 \mathrm{~J}$ [13, 16]. As we will discuss later, extraction rate of green crude is faster than that of water. This implies that DME amount for extraction of green crude is less than that for removing of water. In other words, the required energy for extraction of green crude is less than water. Thus, the available calorific value for extraction of green crude oil from microalgae is less than 1,109 $\times 9=9,981 \mathrm{Jg}^{-1}$. Therefore, the proposed method is more energy efficient than the conventional method from the perspective of energy balance.

Considering both the need for sustainable energy and environmental concerns, this method was initially tested on a natural blue-green microalga (a species usually causing harmful algal blooms in human ecosystems) collected at Hirosawa Mere in Kyoto City, Japan [12]. By using dimethyl ether (293 K, $0.51 \mathrm{MPa}$ ) as an extractant, the green crude was successfully extracted from natural blue-green microalgae (91.0\% water content) with a high extraction capacity of $40.1 \%$ of the dry weight of the microalgae. The extraction yield by liquefied DME was $99.7 \%$. The resulting green crude was further analyzed by GC-MS, and the result showed that the lipid substance was predominant chemical composition in the extracted green crude. The calorific value of the green crude was $45,790 \mathrm{~J} \mathrm{~g}^{-1}$.

The practical application of this method will require fundamental research to evaluate its effectiveness for different types of algae. In this study, we investigate the extraction yield of green crude by liquefied DME on several natural blue-green microalgae and the results were compared to the Bligh-Dyer's method. 


\section{Methodology}

\subsection{Materials}

The samples were five selected species of microalgae and two mixed-species of microalgae as follows. (i, ii) Oscillatoria agardhii NIES-595 and NIES-1263, collected in Northern Ireland, and Germany, respectively. The water contents of both microalgae were $85.0 \%$. (iii, iv) Microcystis aeruginosa ONC and GSK, collected in the main Okinawa island, Japan. The water contents were 93.4 and $91.1 \%$, respectively. (v) Monoraphidium chlorophyta GK 12. The water content was $78.2 \%$. (vi) Mixed-species (mainly Cymbela) collected at Lake Kanogawa in Ozu City, Japan. The water content was 93.0 \%. (vii) The same sample used in the previous study [12]. Mixed-species (mainly Microcystis) collected at Hirosawa Mere in Kyoto City, Japan. The water content was $91.0 \%$.

\subsection{Experimental apparatus and methods}

The experimental apparatus was the same as that described in the previous study [12]. Briefly, a vessel used for storing liquefied DME (volume: $100 \mathrm{~cm}^{3}$; TVS-1-100, Taiatsu Techno Corp., Saitama, Japan), a vessel as an extraction column (diameter, $11.6 \mathrm{~mm}$; length, $190 \mathrm{~mm}$; HPG-10-5, Taiatsu Techno Corp.) and a storage vessel for a mixture of DME, water and extracted crude oil (HPG-96-3, Taiatsu Techno Corp.) were connected in series. The microalgae sample was loaded into the lower half of the extraction column and the upper half was loaded with glass beads (of diameter between 0.71 and $0.99 \mathrm{~mm}$; BZ-08, Asone Co., Inc., Osaka, Japan). Nitrogen gas (0.51 MPa) was supplied to flow through the extraction system. The DME flow rate was $10 \mathrm{~cm}^{3} \mathrm{~min}^{-1}$, and the temperature was $293 \mathrm{~K}$. The experiments were all performed three times independently and the data reported in this paper are the mean values with \pm deviation.

\subsection{Total crude oil content}

The total crude oil content was determined using a widely-used gravimetric analysis based on Bligh-Dyer's method [8]. Briefly, 1g of the dried microalgae was mixed and homogenized with chloroform-methanol (1:1 vol/vol). An equivalent volume of distilled water was added to the microalgae and chloroform-methanol mixtures. Subsequently, the mixtures were transferred into a separatory funnel and agitated for 5 minutes. The mixtures separated into double layers of water-methanol and chloroform phases. The green crude dissolved easily in the low-polar chloroform phase. The green crude in the chloroform layer was separated from the separatory funnel and the separated chloroform was evaporated under reduced pressure.

\section{Results and Discussion}

\subsection{Extraction of green crude from several microalgae}

The extraction rate and yield of green crude on the blue-green microalgae by liquefied DME was examined. We would emphasize that the microalgae had high moisture and unbroken cell walls, in the extraction with sufficient liquefied DME. The extraction volumes achieved by liquefied DME and the Bligh-Dyer's method were respectively shown in Fig. 1. White expresses the green crude extraction rate by liquefied DME on the dry weight of the microalgae. Black expresses the results of the Bligh-Dyer's method. The superscript "an" represents the extraction yield of the DME extraction method relative to the Bligh-Dyer's method. 


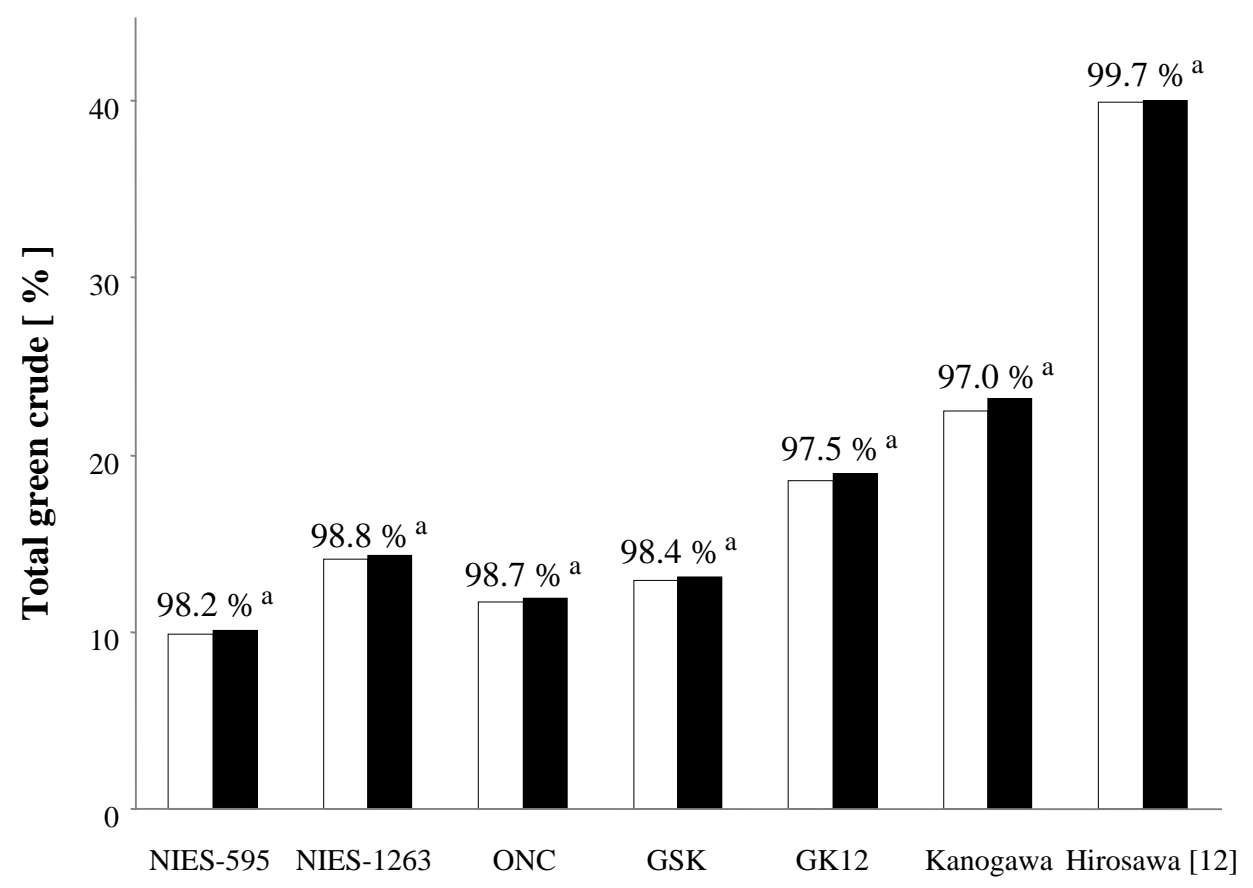

Fig. 1. Green crude extraction rate and yields on several microalgae.

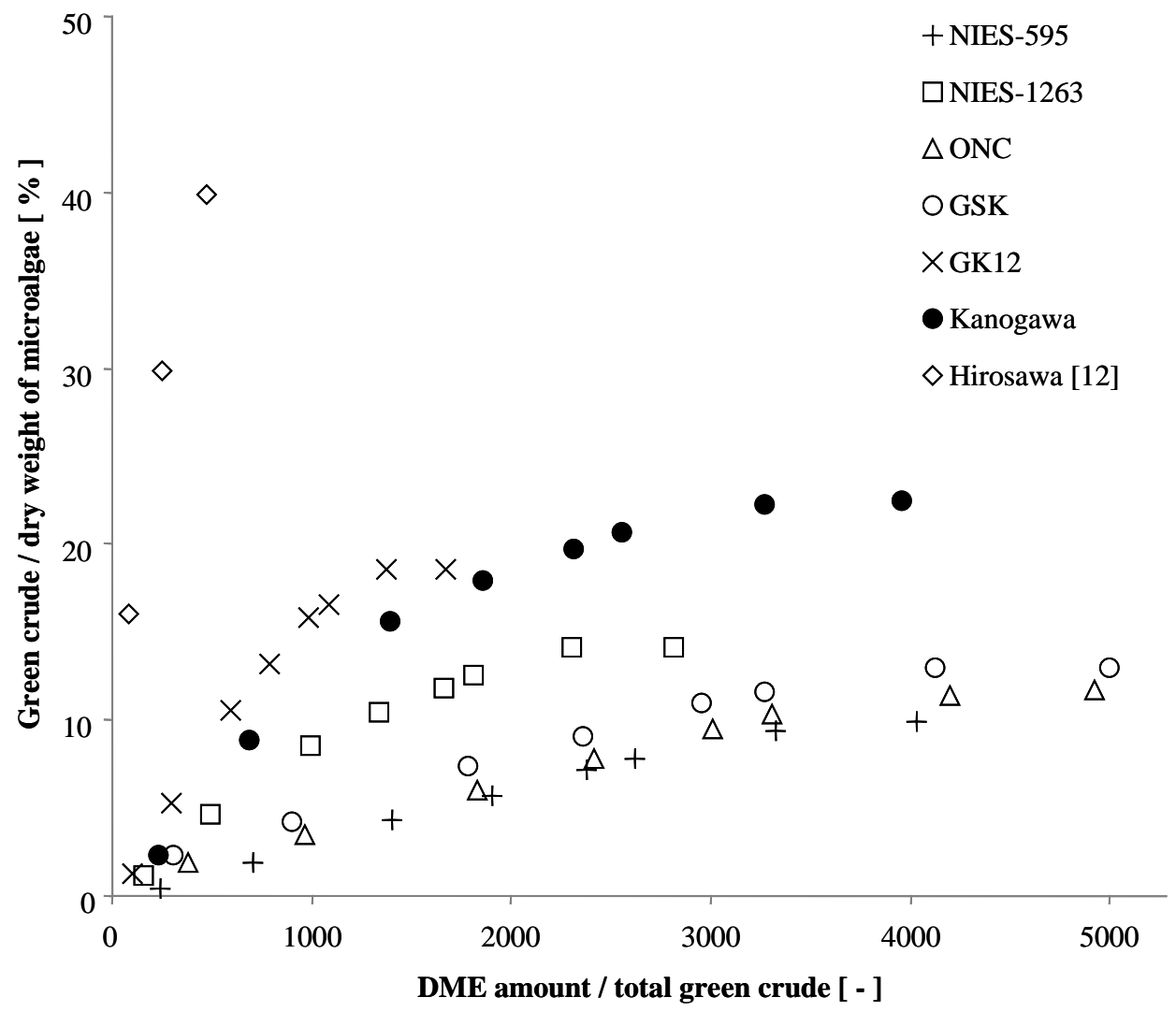

Fig. 2. Extraction of green crude from several microalgae by liquefied DME. 
Both NIES-595 and NIES-1263 belong to Oscillatoria agardhii, but their extraction rates differ as $9.9 \pm 1 \%$ and $14.0 \pm 1 \%$, respectively. Conversely, the extraction rates of ONC 11.0 $\pm 2 \%$ and GSK $12.0 \pm 1.5 \%$ are similar. The extraction rate of GK12 was $18.5 \pm 2 \%$. The extraction rate of the mixed-species of microalgae collected at Lake Kanogawa was $22.5 \pm$ $1 \%$. The extraction rate of Hirosawa Mere showed the highest extraction rate of $40.1 \pm 2 \%$.

The extraction yield of all species achieved more than $97.0 \%$ of total crude oil as determined by the Bligh-Dyer's method. This implies that the DME extraction method provides comparable results to the Bligh-Dyer's method.

The extraction efficiency of green crude by liquefied DME on these microalgae was shown in Fig. 2. For each of the samples, the liquefied DME amount was converted into a ratio of the DME amount relative to total green crude, since the total green crude amount differed. In general, solvent is reused until the green crude concentration in the solvent increases sufficiently, whereupon the usual solvent ratio may apparently be much smaller. On the other hand, in this study, the liquefied DME was not reused after extraction, hence the liquefied DME ratio must be large.

The DME amounts required to reach equilibrium in the extraction of green crude in increasing order were Hirosawa < GK12 < NIES-1263 < Kanogawa < NIES-595 < ONC < GSK. This sequence almost corresponds with the total green crude amount.

\subsection{Dewatering from several microalgae}

The dewatering by liquefied DME on these microalgae was shown in Fig. 3. Since the water content also differed for each of the samples, the liquefied DME was converted into the ratio

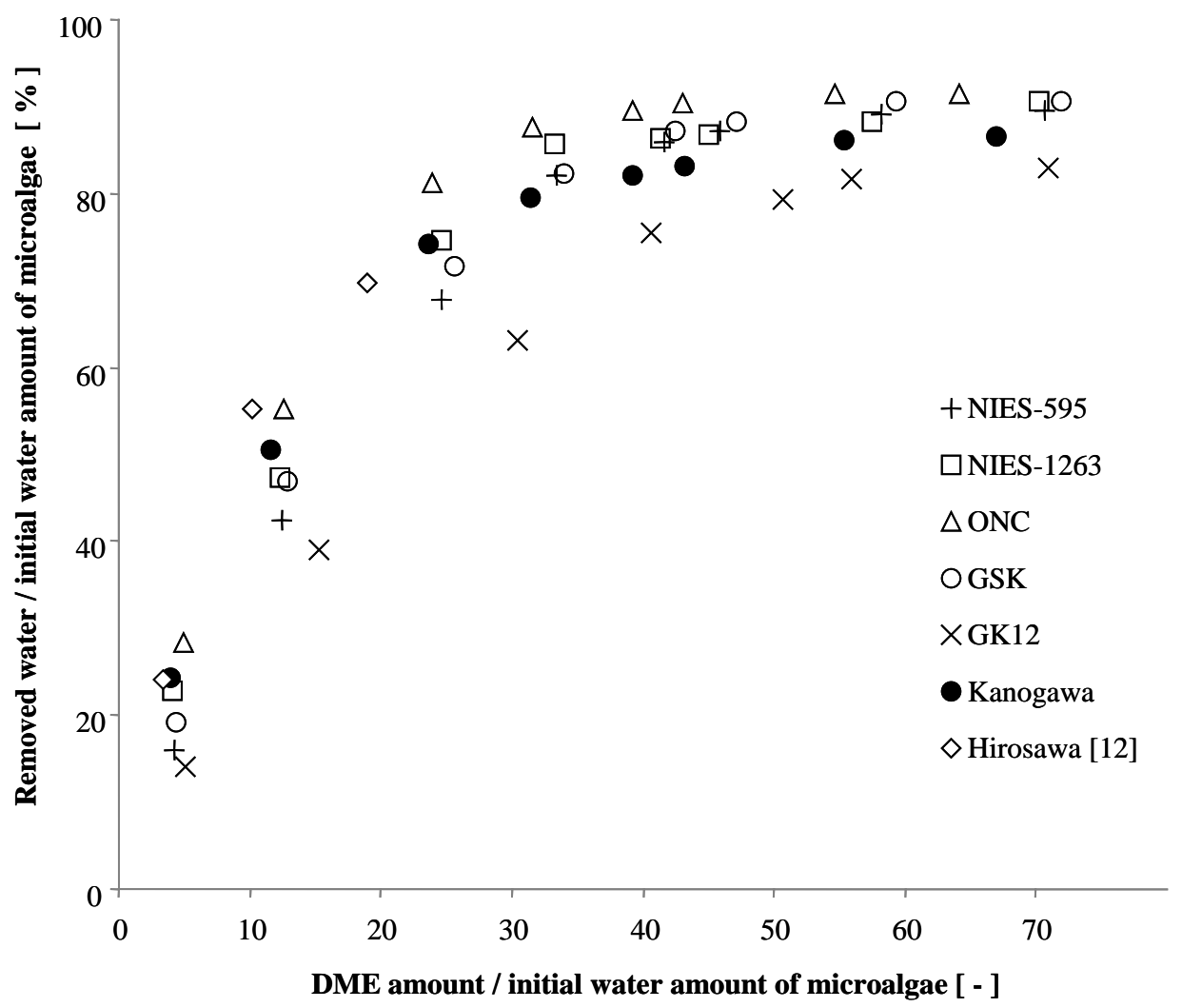

Fig. 3. Dewatering of several microalgae by liquefied DME. 
of the DME amount relative to initial water content. By increasing the amount of liquefied DME, the water was extracted from the high-moisture microalgae together with green crude. Moreover, no obvious difference was observed in the dewatering for all samples. While green crude is confined in the microalgae cell wall, most of water exist outside the microalgae cell wall. This make a difference between the green crude extraction and the dewatering.

\section{Conclusions}

This study confirmed the direct extraction of green crude from several high-moisture natural microalgae by using liquefied DME. Moreover, the extracted amount was almost equal to the Bligh-Dyer's method. Here it is notable that conventional methods are unable to directly extract green crude from high-moisture microalgae, and the cell disruption must be carried out before solvent extraction. The other advantage of this method is the dewatering effect. This method has the potential to reuse the removed water as microalgae broth. The materials in the removed water will be examined from the perspective of the water shortage crisis.

\section{Acknowledgements}

This research was supported by a grant from the Industrial Technology Research Program (Project ID: 09B40009c) of the New Energy and Industrial Technology Development Organization (NEDO). We are deeply grateful to Drs. Tadaaki Tokashiki, Tsuyoshi Ikehara, Mina Yasumoto-Hirose and Atsushi Yoshino at the Tropical Technology Center, Associate Professor Katsuhiko Fujii at Yamaguchi University, and Mr. Tomoyuki Akasaka at the Ozu City government for providing the microalgae.

\section{References}

[1] M. Xin, Y. Jianming, X. Xin, Z. Lei, N. Qingjuan, X. Mo, Biodiesel production from oleaginous microorganisms. Renewable Energy 34, 2009, pp.1-5.

[2] B.J. Gallagher, The economics of producing biodiesel from algae. Renewable Energy 36, 2011, pp. 158-162.

[3] B. Liam, O. Philip, Biofuels from microalgae- A review of technologies for production processing, and extraction of biofuels and co-products. Renewable and Sustainable Energy Reviews 14, 2010, pp. 557-577.

[4] A. Demirbas, S. Science, T. Turkey, Production of biodiesel from algae oils. Energy Sources, Part A, 31, 2009, pp. 163-168.

[5] X. Miao, Q. Wu, Biodiesel production from heterotrophic microalgal oil. Bioresource Technology 97, 2006, pp. 841-846.

[6] C. Posten, G. Schaub, Microalgae and terrestrial biomass as source of fuels- A process view. Journal of Biotechnology 14, 2009, pp. 64-69.

[7] E. Molina Grima, E. Belarbi, F. Fernandez, A. Medina, Y. Chisti, Recovery of microalgal biomass and metabolites: process options and economics. Biotechnology Advances 20, 2003, pp. 491-515.

[8] E.G. Bligh, W.J. Dyer, A rapid method of lipid extraction and purification. Canadian Journal of Biochemistry and Physiology 37, 1959, pp. 911-917. 
[9] L. Jae-Yon, Y. Chan, J. So-Young, A. Chi-Yong, O. Hee-Mock, Comparison of several methods for effective lipid extraction from microalgae. Bioresource Technology 101, 2010, pp. 75-77.

[10]C. Samori, C. Torri, G. Samori, D. Fabbri, P. Galletti, F. Guerrini, R. Pistocchi, E. Tagliavini, Extraction of hydrocarbons from microalga Botryococcus braunii with switchable solvents. Bioresource Technology 101, 2010, pp. 3274-3279.

[11]M. Zhu, P.P. Zhou, L.J.Yu, Extraction of lipids from Mortierella alpine and enrichment of arachidonic acid from the fungal lipids. Bioresource Technology 84, 2002, pp. 93-93.

[12]H. Kanda, P. Li, Simple extraction method of green crude from natural blue-green microalgae by dimethyl ether. Fuel 2010, doi:10.1016/j.fuel.2010.10.057.

[13]H. Kanda, H. Shirai, Method for removing water contained in solid using liquefied material. 2002, Patent number - JP 4291772 B2 WO2003/101579.

[14]H. Kanda, Y. Urakawa, Method for dehydrating water-containing substance using liquefied matter. 2006, Patent number - US 7803253 B2.

[15]H. Kanda, H. Makino, M. Miyahara, Energy-saving drying technology for porous media using liquefied DME gas. Adsorption 14, 2008, pp. 467-473.

[16] H. Kanda, H. Makino, Energy-efficient coal dewatering using liquefied dimethyl ether. Fuel 89, 2010, pp. 2104-2109.

[17] H. Kanda, Method for deoiling oil-containing substance using liquefied material. 2006, Patent number - JP 4542517 B2.

[18] H. Kanda, H. Makino, Clean up process for oil-polluted materials by using liquefied DME. Journal of Environment and Engineering 4, 2009, pp. 356-361.

[19] K. Oshita, M. Takaoka, S. Kitade, N. Takeda, H. Kanda, H. Makino, T. Matsumoto, S. Morisawa, Extraction of PCBs and water from river sediment using liquefied dimethyl ether as an extractant. Chemosphere 78, 2010, pp. 1148-1154.

[20] H. Holldorff, H. Knapp, Binary vapor-liquid-liquid equilibrium of dimethyl ether-water and mutual solubilities of methyl chloride and water: experimental results and data reduction. Fluid Phase Equilibria 44, 1988, pp. 195-209.

[21] TA. Semelsberger, RL. Borup, HL. Greene, Dimethyl ether (DME) as an alternative fuel. Journal of Power Sources 156, 2006, pp. 497-511. 